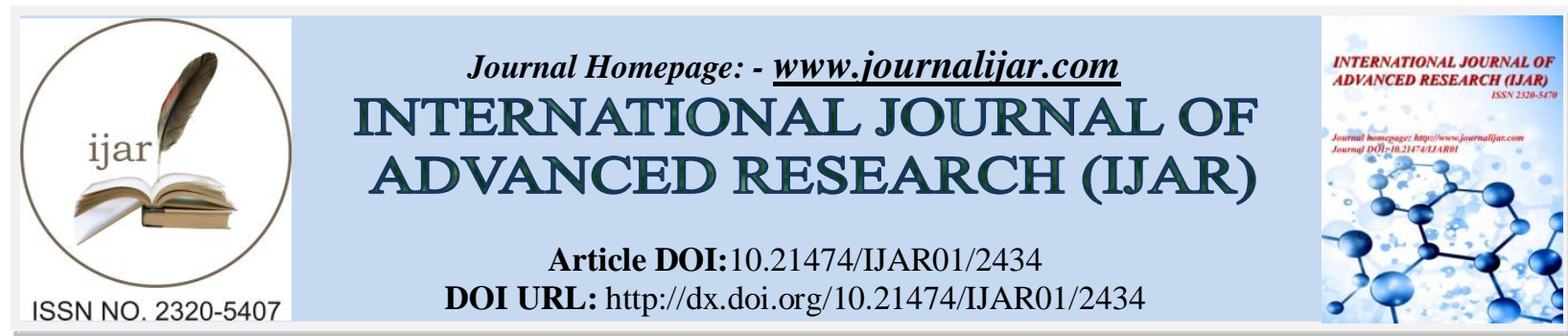

RESEARCH ARTICLE

\title{
EPIDEMIOLOGY OF ACNE VULGARIS IN ADOLESCENT AND YOUNG FEMALES IN RIYADH CITY, KINGDOM OF SAUDI ARABIA.
}

\section{Nagah Mohamed Abo El-Fetoh ${ }^{1}$, RawanSaeedAlghamdi ${ }^{2}$, Wijdan Ahmed Albarqi ${ }^{2}$, Safiah Ali Mohammad Asiri $^{2}$ and Noura Qadhab Alruwaili ${ }^{3}$.}

1. Department of Public Health and Community Medicine, Faculty of Medicine, Northern Border University, KSA.

2. Intern, Faculty of Medicine, King Khaled University, Abha, KSA.

3. Intern, Faculty of Medicine, Northern Border University.

\section{Manuscript Info}

\section{Manuscript History}

Received: 20 October 2016

Final Accepted: 22 November 2016

Published: December 2016

Key words:-

Acne vulgaris;Adolescents; female; dietary factors; seasonal variation;

Riyadh; Kingdom of Saudi Arabia.

\section{Abstract}

Background:Acne vulgaris remains one of the most common diseases to afflict humanity,with over $90 \%$ of males and $80 \%$ of females affected by the age of 21 years. The condition usually starts in adolescence, peaks at the ages of 14 to 19 years and frequently resolves by mid-twenties. Acne vulgaris develops earlier in females than in males, which may reflect the earlier onset of puberty in females. The most severe forms of acne vulgaris occur more frequently in males, but the disease tends to be more persistent in females.Objectives:This work was conducted to estimate the prevalence of acne vulgaris, to show the characteristics of cases, to determine the aggravating factors and the psychological impact of acne vulgaris in a sample of adolescent and young females of Riyadh city, KSA.

Participants and methods: It is a cross-sectional study.A total of 403 adolescent and young females during the $2^{\text {nd }}$ half of 2016were included in the study. Data was collected via filling-in an online questionnaire. Results: the overall prevalence of acne vulgaris was $68.2 \%$. Mean age of acne cases $( \pm$ SD) was $21.21(( \pm 4.6)$ and the mean age of onset of acne $( \pm$ SD) was $15.5( \pm 2.9)$. Positive family history of acne vulgaris was found in $42.5 \%$ of cases. The skin was greasy in $72.7 \%$ of cases. Acne site was the face in $46.2 \%$, the back in $3.6 \%$ and multiple sites in $50.2 \%$ of the cases. More than half (57.5\%) of cases had first degree acne. Students mentioned several factors affecting the appearance of acne; 56\% reported increased acne appearance before menstruation, $10.5 \%$ during pregnancy, $70.5 \%$ defective skin cleaning, $77.1 \%$ stress, 33.8 eating of chocolate, $31.3 \%$ fatty meals, $4.0 \%$ with spicy food, $2.9 \%$ with excess carbonated beverages drinks, $61.5 \%$ reported increased acne appearance in summer months. $57.8 \%$ of cases reported impact of acne on social relations and $54.2 \%$ had an impact on self confidence. Conclusion and recommendations: Acne was highly prevalent among adolescents and young females in Riyadh city, KSA. Several risk factors increased the appearance of acne including skin cleanliness, 
certain diets, stress and menstruation. There was clear seasonal variation; mainly in Summer. Therefore, a community-based multiple strategies are required to combat with increasing rate of acne vulgaris and its subsequent complications among adolescent and adult females in Riyadh city and to educate them about its causes and the risk factors aggravatingits development.

Copy Right, IJAR, 2016,. All rights reserved.

\section{Introduction:-}

Acne vulgaris remains one of the most common diseases to afflict humanity, ${ }^{[1]}$ with over $90 \%$ of males and $80 \%$ of females affected by the age of 21 years. ${ }^{[2]}$

Acne vulgaris (or simply acne) is a long-term skin disease that occurs when hair follicles become clogged with dead skin cells and oil from the skin. Acne vulgaris is a chronic condition that is virtually universal in adolescence ${ }^{(3)}$. The condition usually starts in adolescence, peaks at the ages of 14 to 19 years and frequently resolves by mid-twenties. Acne vulgaris develops earlier in females than in males, which may reflect the earlier onset of puberty in females. The most severe forms of acne vulgaris occur more frequently in males, but the disease tends to be more persistent in females. ${ }^{[4]}$

Acne is characterized by areas of blackheads, whiteheads, pimples, and greasy skin, and may result in scarring ${ }^{(\mathbf{5})}$. In girls, the pilo-sebaceous duct becomes smaller between days 15 and 20 of the menstrual cycle and the blockage leads to premenstrual acne. However, the mechanism for this blockage is not known. ${ }^{[6]}$ Stoll et al. ${ }^{[7]}$ found an overall $44 \%$ prevalence of premenstrual flare. ${ }^{[8]}$. Noticed a mean reduction in the non-inflammatory and inflammatory lesions count during the postmenstrual period. Small, non-inflamed acne lesions may not be more than a slight nuisance but, in individuals with more severe inflammatory disease, pain, social embarrassment, and both physical and psychological scarring can be life altering. ${ }^{[9]}$

Food items in general were considered as causes and/or aggravating factors of acne. Fatty food, chocolate, potato chips and spicy food were considered a cause of acne in 53.9\%, 79.4\%, 53.9\%, and 29.4\% of the sample, respectively. In Poli et al. study fatty food, chocolate, and snacks were thought to exacerbate acne by $62 \%$ and $45 \%$ of their sample, respectively ${ }^{[10]}$. In Al-Hoqail study $79 \%$ of acne patients sample believed that acne is related to diet [11]. Stoll et al. study (44\% of their sample experienced premenstrual flares of their acne) ${ }^{[12]}$.

A study conducted in India, revealed that, The mean age of the study group was 19.78 (SD \pm 4.94$)$ years. years. The mean age of onset was 15.9 ( $\mathrm{SD} \pm 3.00$ ) years. Grade 1 was the most common as it affected $60.2 \%$ of the participants. There was a higher incidence of scarring (39.5\%) and post-acne hyperpigmentation (24.6\%). In female patients, $57.7 \%$ had premenstrual flare and $12.4 \%$ had cutaneous markers of androgenicity. There was no association between severity of acne vulgaris and other markers of androgenicity. Seasonal variation was observed only in 80 patients $(25.9 \%) ; 71$ patients $(23 \%)$ exacerbated in summer and 9 patients $(2.9 \%)$ in winter. Smokers had more severe grade of acne vulgaris compared to nonsmokers ${ }^{[13]}$. Another study carried out in Malyzia in (2009) on secondary school adolescents, found that the prevalence of facial acne among the adolescents was $67.5 \%$, increased with increasing age and was more common among males $(71.1 \%)$ than females $(64.6 \%)^{[14]}$.

This work was conducted to estimate the prevalence of acne vulgaris, to describe the characteristics of cases, to determine the aggravating factors and the psychological impact of acne vulgaris in a sample of adolescent and young females of Riyadh city, KSA.

\section{Subjects and Methods:-}

A cross-sectional study was conducted among a sample of adolescent and young females of Riyadh city, KSA during the academic year 2015-2016.The sample size was calculated using the sample size equation $n=z^{2} * p(1-p) / e^{2}$ considering the prevalence of acne vulgaris in Riyadh is 50\%, target population more than 1000 and study power $95 \%$. The minimum size required is 400 adolescent and young females. An online questionnaire was disseminated to the targeted population to complete it. The parameters included in the questionnaire included age, gender, other 
important socio-demographic dataas educational status and mean family income/month (in SR), age of onset of acne, site and grade of acne, and its relation to skin cleanliness, certain type of food, seasonal variation, history of treatment and history of plastic surgery. A total of 403 questionnaires was completed. Researchers Explained to the participants the different grades of acne in the introduction of the questionnaires. Acne vulgaris was graded using a simple grading system, taking into account the predominant lesion to grade acne, which classifies acne vulgaris into four grades. ${ }^{[15]}$

Grade 1: facial involvement with comedones and fewer than 10 inflammatory lesions,

Grade 2: facial involvement with comedones and 10-20 inflammatory lesions,

Grade 3: inflammatory lesions at trunk with or without facial involvement,

Grade 4: inflammatory lesions with nodules and presence of scars at face or trunk.

\section{Ethical considerations:-}

Permission to conduct the study was obtained from the Research and Ethics Committee at the College of Medicine, King Saud University, Riyadh , Saudi Arabia. Data collector gave a brief written introduction to the participants by explaining the aims and benefits of the study. Anonymity and confidentiality of data was maintained throughout the study. There was no conflict of interest.

\section{Statistical Analysis:-}

We utilized the Statistical Package for Social Sciences (SPSS Inc., Chicago, IL, USA) version 16 to analyze the study data. Results are displayed as counts and percentages. The chi square and independent sample t tests was used as a tests of significance, and differences were considered significant at $\mathrm{P}$ value less than 0.05.

\section{Results:}

Table (1) illustrates the percentage of acne ,nationality ,education level, average family history ,family history of acne ,using of hormonal contraception ,skin type and smoking history among studied participants. The percentage of acne cases was $(68.2 \%)$. More than third (38.0\%) of the participants were 15-20 years, followed by the age group $20-25$ years $(53.5 \%)$, only $9.4 \%$ were $\leq 15$ years and $6.9 \%$ were $<30$ years. Mean age of the participants $( \pm$ SD) was $22.08( \pm 6.8)$. Most of studied participants $(96.8 \%)$ were Saudi. More than a third of them $(37.5 \%)$ were university graduates and only $(6 \%)$ had completed their primary education. The highest percentage (33\%) have average family income/month 5000-10000 SR and (21.1\%) have (10000-15000 SR). The majority of studied participants $(90.6 \%)$ weren't using hormonal contraception, and about $(39.7 \%)$ of them had family history of acne among parents and brothers. More than half of them (66.7\%) had oily skin, almost all of them (98.5\%) were non smoker.

Table (2) illustrate the degree of acne, age of appearance, family history, skin type and presence of skin marks of acne after cure in studied acne cases $(n=275)$. More than half of cases $(57.5 \%)$ had first degree acne vulgaris, followed by third degree $(16.4 \%)$, then the second degree in $(16 \%)$ and fourth degree in only $(10.2 \%)$ of cases. In less than half of cases $(43.3 \%)$ acne started to appear at age of 12-15 years, in more than third (37.8\%) it started at the age of 15-18 years, and in about fifth (18.9\%) of cases it started to appear at age of 18 years and more. Mean age of appearance $( \pm$ SD) was $15.51( \pm 2.97)$. In half of cases $(50.2 \%)$, acne was most likely tobe in multiple sites (face, chest and shoulders), followed by face only in less than half (46.2\%), and in the back and shoulders only in just $(3.6 \%)$ of cases. In less than half $(42.5 \%)$ of cases there were positive family history of acne vulgaris. Most of cases $(72.7 \%)$ have greasy skin, and about $(74.9 \%)$ reported presence of scarring and post-acne hyperpigmentation.

Table (3) illustrates factors aggravating the appearance of acne vulgaris in studied acne cases. About half of cases $(56 \%)$ reported increased acne appearance before menstruation, 16\% reported increased acne duding menstruation and more than quarter $(25.8 \%)$ showed no relation of acne to menstrual cycle. The majority of cases (70.5) reported relation of increased appearance of acne to defective skin cleaning and (77.1\%) to stress. In more than third of cases $(33.8 \%)$ there was increase appearance with consumption of chocolate, $(31.3 \%)$ with consumption fatty food, (4.0\%) with spicy food, $(2.9 \%)$ with consumption of carbonated beverages and (18.9\%) there was increase appearance with consumption of all the previous food (chocolate, fatty food, spicy food and drinking carbonated beverages). Regarding relation of acne to pregnancy, most of cases $(80.7 \%)$ reported no relation, $10.5 \%$ reported increase of acne during pregnancy and $8.7 \%$ reported decrease of acne during pregnancy. The season of increased appearance of acne was more likely to be summer in most of cases $(61.5 \%)$ while about $(34.5 \%)$ of cases showed no seasonal variation of the appearance of acne vulgaris. Majority of cases $(98.2 \%)$ were non smokers. 
Table (4) demonstrates presence of psychic depression due to acne, effect of acne on social relations and on self confidence among the studied acne vulgaris cases. Most of cases (82.6\%) reported feeling of depression due to appearance of acne, more than half (57.8\%) of cases reported impact of acne on social relations and $54.2 \%$ had an impact on self confidence.

Table (5) illustrates history of medical or surgical treatment of acne and source of information about acne among the studied acne vulgaris cases. Most of the cases (67.6\%) received medical treatment of acne, only (4.7\%) had plastic surgery for acne. Only about third of cases (31.2\%) got their information from physicians, and about (14.6\%) from friends.

Table (6) illustrates the relationship between presence of acne and skin type, average monthly family income and using of hormonal contraception among the studied participants.Positive family history of acne vulgaris was found in about half of cases of acne (42.5\%) with a statistically significant difference ( $\mathrm{p}$ value $=0.05$ ). the majority (72.7\%) of the affected students were more likely to have fatty skin compared with (53.9)\% of students without acne and the difference was statistically significant ( $\mathrm{p}$ value $=0.000$ ). There is significant effect of average family income/month ( $\mathrm{p}$ value $=0.056$ ), but no significant effect of using of hormonal contraception on presence of acne among studied participants.

Table (1): percentage distribution of the presence of acne, age group, nationality, educational level, average family income, family history of, using of hormonal contraception, skin type and smoking history in the studied participants, Riyadh, KSA.

\begin{tabular}{|c|c|c|}
\hline & Frequency $(n=403)$ & Percent \\
\hline \multicolumn{3}{|l|}{ Presence of acne } \\
\hline • Yes & 275 & 68.2 \\
\hline$\bullet \quad \mathrm{No}$ & 128 & 31.8 \\
\hline \multicolumn{3}{|l|}{ Age group (in years) } \\
\hline$\bullet \leq 15$ & 38 & 9.4 \\
\hline - $15-20$ & 153 & 38.0 \\
\hline - $20-25$ & 143 & 35.5 \\
\hline - $25-30$ & 41 & 10.2 \\
\hline$\bullet \quad>30$ & 28 & 6.9 \\
\hline Mean age $( \pm \mathrm{SD})$ & \multicolumn{2}{|l|}{$22.08( \pm 6.8)$} \\
\hline Mean age of acne cases $( \pm \mathrm{SD})$ & \multicolumn{2}{|l|}{$21.21(( \pm 4.6)$} \\
\hline \multicolumn{3}{|l|}{ Nationality } \\
\hline$\bullet \quad$ Saudi & 390 & 96.8 \\
\hline • Others & 13 & 3.2 \\
\hline \multicolumn{3}{|l|}{ Educational level } \\
\hline - $\quad$ Read and write & 24 & 6.0 \\
\hline - $\quad$ Primary & 24 & 6.0 \\
\hline - $\quad$ Preparatory & 63 & 15.7 \\
\hline - $\quad$ Secondary & 120 & 29.8 \\
\hline - University or more & 151 & 37.5 \\
\hline \multicolumn{3}{|c|}{ Average family income/month (SR) } \\
\hline$\bullet \quad<5000$ & 67 & 16.6 \\
\hline - $5000-10000$ & 133 & 33.0 \\
\hline $\begin{array}{ll} & 10000-15000\end{array}$ & 85 & 21.1 \\
\hline - $15000-20000$ & 55 & 13.6 \\
\hline$\bullet \quad>20000$ & 67 & 16.6 \\
\hline \multicolumn{3}{|l|}{ Using of hormonal contraception } \\
\hline$\bullet \quad$ No & 365 & 90.6 \\
\hline - $\quad$ Yes & 38 & 9.4 \\
\hline \multicolumn{3}{|l|}{ Family history of acne } \\
\hline - Yes & 160 & 39.7 \\
\hline
\end{tabular}




\begin{tabular}{|c|l|l|}
\hline$\bullet \quad$ No & 243 & 60.3 \\
\hline Skin type & \multicolumn{2}{l|}{} \\
\hline$\bullet \quad$ Dry skin & 134 & 33.3 \\
\hline$\bullet$ Oily skin & 269 & 66.7 \\
\hline Smoking history & & \\
\hline$\bullet \quad$ No & 397 & 98.5 \\
\hline$\bullet$ Ex-smoker & 2 & .5 \\
\hline$\bullet$ Smoker & 4 & 1.0 \\
\hline
\end{tabular}

Table (2): Degree, age of appearance, site, family history, skin type and presence of skin marks of acne after cure among studied acne vulgaris cases of participants, Riyhad, KSA $(n=275)$

\begin{tabular}{|c|c|c|}
\hline & Frequency $(\mathrm{n}=275)$ & Percent \\
\hline \multicolumn{3}{|l|}{ Degree of acne } \\
\hline - First degree & 158 & 57.5 \\
\hline - Second degree & 44 & 16.0 \\
\hline • $\quad$ Third degree & 45 & 16.4 \\
\hline - Forth degree & 28 & 10.2 \\
\hline \multicolumn{3}{|l|}{ Age of appearance } \\
\hline$\bullet \quad 12-$ & 119 & 43.3 \\
\hline - 15 - & 104 & 37.8 \\
\hline • $18+$ & 52 & 18.9 \\
\hline Mean age of appearance $( \pm$ SD) & \multicolumn{2}{|l|}{$15.51( \pm 2.97)$} \\
\hline \multicolumn{3}{|l|}{ Site of acne } \\
\hline$\bullet \quad$ Face only & 127 & 46.2 \\
\hline - $\quad$ Face, chest, back and shoulders (multiple sites) & 138 & 50.2 \\
\hline - $\quad$ Back and shoulders only & 10 & 3.6 \\
\hline \multicolumn{3}{|l|}{ Family history of acne } \\
\hline - Yes & 117 & 42.5 \\
\hline$\bullet \quad$ No & 158 & 57.5 \\
\hline \multicolumn{3}{|l|}{ Skin type } \\
\hline$\bullet \quad$ Dry skin & 75 & 27.3 \\
\hline$\bullet \quad$ Greasyskin & 200 & 72.7 \\
\hline \multicolumn{3}{|l|}{ Scarring and post-acne hyperpigmentation } \\
\hline - Yes & 250 & 74.9 \\
\hline - $\quad$ No & 84 & 25.1 \\
\hline
\end{tabular}

Table (3): Factors aggravating the appearance of acne vulgaris in studied acne cases among the studied acne vulgaris cases $(\mathrm{n}=275)$. KSA

\begin{tabular}{|c|c|c|}
\hline & Frequency & Percent \\
\hline \multicolumn{3}{|l|}{ Relation to menstrual cycle } \\
\hline - Increased before menstruation & 154 & 56.0 \\
\hline - $\quad$ Increased duding menstruation & 44 & 16.0 \\
\hline - $\quad$ Increased after menstruation & 6 & 2.2 \\
\hline - No relation & 71 & 25.8 \\
\hline \multicolumn{3}{|l|}{ Relation of acne to skin cleaning } \\
\hline - $\quad$ Yes & 194 & 70.5 \\
\hline$\bullet \quad$ No & 81 & 29.5 \\
\hline \multicolumn{3}{|l|}{ Relation of acne to stress } \\
\hline - Yes & 212 & 77.1 \\
\hline$\bullet \quad$ No & 63 & 22.9 \\
\hline \multicolumn{3}{|l|}{ Relation of acne to food } \\
\hline - Chocolate & 93 & 33.8 \\
\hline
\end{tabular}




\begin{tabular}{|c|c|c|}
\hline - $\quad$ Fatty food & 86 & 31.4 \\
\hline - $\quad$ Spicy food & 11 & 4.0 \\
\hline - Carbonated beverages & 8 & 2.9 \\
\hline - $\quad$ All of the above & 52 & 18.9 \\
\hline - No relation to certain food & 25 & 9.1 \\
\hline \multicolumn{3}{|l|}{ Relation of acne to pregnancy } \\
\hline$\bullet \quad$ No relation & 222 & 80.7 \\
\hline $\begin{array}{ll} & \text { Increased during pregnancy } \\
\end{array}$ & 29 & 10.5 \\
\hline - $\quad$ Decreased during pregnancy & 24 & 8.7 \\
\hline \multicolumn{3}{|l|}{ Seasonal increase of acne } \\
\hline$\bullet \quad$ Autumn & 1 & 0.4 \\
\hline - $\quad$ Spring & 1 & 0.4 \\
\hline - Winter & 9 & 3.3 \\
\hline - $\quad$ Summer & 169 & 61.5 \\
\hline - No relation to certain season & 95 & 34.5 \\
\hline \multicolumn{3}{|l|}{ Smoking } \\
\hline - Non smokers & 328 & 98.2 \\
\hline - Ex smokers & 2 & .6 \\
\hline - $\quad$ Smokers & 4 & 1.2 \\
\hline
\end{tabular}

Table (4): Presence of psychic depression due to acne effect of acne on social relations and self confidence among the studied acne vulgaris cases $(n=275)$.

\begin{tabular}{|c|c|c|}
\hline 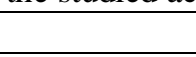 & Frequency $(n=275)$ & Percent \\
\hline \multicolumn{3}{|c|}{ Psychic depression due to acne } \\
\hline - Yes & 276 & 82.6 \\
\hline - $\mathrm{No}$ & 58 & 17.4 \\
\hline \multicolumn{3}{|c|}{ Effect of acne in social relations } \\
\hline - Yes & 159 & 57.8 \\
\hline$\bullet \quad$ No & 116 & 42.2 \\
\hline \multicolumn{3}{|c|}{ Effect of acne in self confidence } \\
\hline - $\quad$ Yes & 149 & 54.2 \\
\hline - $\quad$ No & 126 & 45.8 \\
\hline
\end{tabular}

Table (5): History of medical or surgical treatment of acne and source of information about acne among the studied acne vulgaris cases of the participants.

\begin{tabular}{|c|l|l|}
\hline Parameter & Frequency $(\mathrm{n}=334)$ & Percent \\
\hline History of medical treatment of acne & \multicolumn{2}{l|}{} \\
\hline$\bullet \quad$ Yes & 186 & 67.6 \\
\hline$\bullet \quad$ No & 89 & 32.4 \\
\hline History of surgical treatment of acne & \multicolumn{2}{l|}{} \\
\hline$\bullet \quad$ Yes & 13 & 4.7 \\
\hline$\bullet \quad 262$ & 95.3 \\
\hline Source of information about acne & \multicolumn{2}{l|}{} \\
\hline$\bullet \quad$ Physician & 86 & 31.2 \\
\hline$\bullet \quad$ Friends & 40 & 14.6 \\
\hline$\bullet \quad 26$ & 9.5 \\
\hline$\bullet \quad$ TV & 26 & 9. \\
\hline$\bullet \quad$ Magazines & 25 & 8.0 \\
\hline$\bullet \quad$ Pharmacists & 22 & 8.0 \\
\hline$\bullet \quad$ School & 22 & 8.5 \\
\hline$\bullet \quad$ Parents & 23 & 11.3 \\
\hline
\end{tabular}


Table (6): Relationship between presence of acne and skin type, average monthly family income, using of hormonal contraception and smoking among the studied participants.

\begin{tabular}{|c|c|c|c|c|c|c|}
\hline & \multicolumn{2}{|c|}{ Presence of acne } & \multirow[t]{2}{*}{ Total } & \multirow[t]{2}{*}{ Chi-Square } & \multirow[t]{2}{*}{$P$ value } \\
\hline & & No $(n=91)$ & Yes $(n=243)$ & & & \\
\hline \multicolumn{7}{|l|}{ Family history of acne } \\
\hline \multirow[t]{2}{*}{$\bullet \quad$ No } & No & 85 & 158 & 243 & \multirow[t]{4}{*}{2.92} & \multirow[t]{4}{*}{0.05} \\
\hline & $\%$ & $66.4 \%$ & $57.5 \%$ & $60.3 \%$ & & \\
\hline \multirow[t]{2}{*}{ - $\quad$ Yes } & No & 43 & 117 & 160 & & \\
\hline & $\%$ & $33.6 \%$ & $42.5 \%$ & $39.7 \%$ & & \\
\hline \multicolumn{7}{|l|}{ Skin type } \\
\hline \multirow{2}{*}{ - Dry } & No & 59 & 75 & 134 & \multirow[t]{4}{*}{31.94} & \multirow[t]{4}{*}{0.000} \\
\hline & $\%$ & $46.1 \%$ & $27.3 \%$ & $33.3 \%$ & & \\
\hline \multirow[t]{2}{*}{ - $\quad$ Greasy } & No & 69 & 200 & 269 & & \\
\hline & $\%$ & $53.9 \%$ & $72.7 \%$ & $66.7 \%$ & & \\
\hline \multicolumn{7}{|c|}{ Average monthly family income (in SR) } \\
\hline \multirow[t]{2}{*}{$\bullet \quad<5000$} & No & 15 & 52 & 67 & \multirow[t]{10}{*}{9.194} & \multirow[t]{10}{*}{0.056} \\
\hline & $\%$ & $11.7 \%$ & $18.9 \%$ & $16.6 \%$ & & \\
\hline \multirow[t]{2}{*}{ - $5000-10000$} & No & 11 & 44 & 55 & & \\
\hline & $\%$ & $8.6 \%$ & $16.0 \%$ & $13.6 \%$ & & \\
\hline \multirow[t]{2}{*}{ - $10000-15000$} & No & 29 & 56 & 85 & & \\
\hline & $\%$ & $22.7 \%$ & $20.4 \%$ & $21.1 \%$ & & \\
\hline \multirow[t]{2}{*}{ - $15000-20000$} & No & 11 & 44 & 55 & & \\
\hline & $\%$ & $8.6 \%$ & $16.0 \%$ & $13.6 \%$ & & \\
\hline \multirow[t]{2}{*}{ - 20000} & No & 24 & 39 & 63 & & \\
\hline & $\%$ & $18.8 \%$ & $14.2 \%$ & $15.6 \%$ & & \\
\hline \multicolumn{7}{|c|}{ Using of hormonal contraception } \\
\hline \multirow[t]{2}{*}{$\bullet \quad$ No } & $\%$ & 106 & 259 & 365 & \multirow[t]{4}{*}{13.22} & \multirow[t]{4}{*}{0.000} \\
\hline & & $82.8 \%$ & $94.2 \%$ & $90.6 \%$ & & \\
\hline \multirow{2}{*}{ - $\quad$ Yes } & & 22 & 16 & 38 & & \\
\hline & & $17.2 \%$ & $5.8 \%$ & $9.4 \%$ & & \\
\hline
\end{tabular}

\section{Discussion:-}

This study was cross-sectional study conducted in Riyadh city, the capital of the of Saudi Arabia in a representative sample of adolescent and young females.

The current study confirms that acne is a common disorder in adolescent and young females as it affected $68.2 \%$ of the studied population. This prevalence was in accordance with findings of a study in Jeddah ${ }^{[16]}$ that reported a prevalence of $64.5 \%$ and $55.5 \%$ were females. Also we are in accordance with a study done in Central Saudi Arabia ${ }^{[17]}$ which found that $56.2 \%$ of the university students had acne. However, our findings are far less than those in Tehran $^{[27]}$ where the overall prevalence of acne was $93.2 \%$ (94.4\% for boys and $92.0 \%$ for girls). The very high rate of acne vulgaris in Iranian adolescents in this study could be explained by genetic background, their skin nature and certain nutrition habits that may increase acne prevalence in this society. In addition, the study population were pupils aged $16+/-0.9$ years, which is the highest affected age group with acne vulgaris.

In the present study, Mean age of acne cases $( \pm$ SD) was 21.21 ( \pm 4.6$)$ and the mean age of onset of acne $( \pm$ SD) was 15.5 ( \pm 2.9$)$. More than half of cases $(57.5 \%)$ had first degree acne vulgaris and (74.9\%) reported presence of scarring and post-acne hyperpigmentation.

These findings are consistent with Indian study which revealed that, The mean age of the study group was 19.78 (SD $\pm 4.94)$ years. The mean age of onset was 15.9 ( $\mathrm{SD} \pm 3.00)$ years. Grade 1 was the most common as it affected $60.2 \%$ of the participants. The mean age of the study group was $19.78(\mathrm{SD} \pm 4.94)$ years and the mean age of onset was $15.9(\mathrm{SD} \pm 3.00)$ years. Grade 1 was the most common as it affected $60.2 \%$ of the participants and there was a higher incidence of scarring $(39.5 \%)$ and post-acne hyperpigmentation $(24.6 \%)^{[13]}$. On the other hand, Al-Ameer and Al-Akloby, ${ }^{[21]}$ in their study of 225 patients with acne vulgaris observed that the age at presentation was $19.2 \pm$ 3.0 years for males and $18.4 \pm 4.2$ years for females, also Adityan and Thappa noted that the mean age of presentation of their patients was 25.58 years. 
In the present study, the prevalence of facial acne was (46.2\%). This finding is less than findings of study carried out in Malyzia in (2009) on secondary school adolescents, found that the prevalence of facial acne among adolescent females was $(64.6 \%)^{[14]}$.

In the current study, about half of cases (56\%) reported increased acne appearance before menstruation, $16 \%$ reported increased acne duding menstruation and more than quarter $(25.8 \%)$ showed no relation of acne to menstrual cycle. These findings aren't in accordance with findings of the study conducted in Damascus, Syria to show the socio-demographic characteristics of acne among university students, reported that, regarding female students, $80 \%$ reported increased acne appearance during their menstruation. ${ }^{[19]}$ But premenstrual flare was noticed in $57.7 \%$ of the 137 female patients in the Indian study. ${ }^{[14]}$ In another study ${ }^{[17]}, 44 \%$ of 400 female participants reported premenstrual flares of their acne in the questionnaires. Which isn't compatible with our study.

In the current study, $77.1 \%$ reported increased acne appearance in relation to stress. However degree of stress and its role with acne formation were stated by many authors ${ }^{[21,22,23]}$. They reported that emotional stress acts as an aggravating risk factor for development of acne. Also ${ }^{[19]}$ confirmed the association between acne prevalence and degree of stress in which we found that students who always were subjected to continuous stress demonstrated higher rate of acne.

A considerable proportion of cases in the current study (70.5\%) believed in a relation of acne appearance to the cleanliness of the skin. This finding agree with results of a study conducted in Syria, which found that, washing face frequently per day in both sexes has a significant relation with a decreased prevalence of acne, as students who wash their faces more than five times per day showed significantly lower prevalence of acne in $23 \%$ males and $22 \%$ of females. ${ }^{[19]}$ The association between acne occurrence and washing face daily in both sexes is in disagreement with several studies as Nottingham study ${ }^{[24]}$ which stated that poor hygiene does not cause acne. Also a systematic review by Magin et al. (2005) stated that, clinicians cannot be didactic in their recommendations regarding diet, hygiene and face-washing, and sunlight to patients with acne. Advice should be individualized, and both clinician and patient cognizant of its limitations. ${ }^{[25]}$

In the current study, in more than third of cases $(33.8 \%)$ there was increase appearance with consumption of chocolate, $(31.3 \%)$ with consumption fatty food, $(4.0 \%)$ with spicy food, $(2.9 \%)$ with consumption of carbonated beverages and (18.9\%) there was increase appearance with consumption of all the previous food (chocolate, fatty food, spicy food and drinking carbonated beverages). Our findings are in accordance with the findings of the study conducted in Australia, which found that $41 \%$ of final year Australian medical students identified the dietary factors (chocolate, oily and fatty foods, and high sugar content foods) as exacerbating factors in acne ${ }^{[26]}$ but their results regarding spicy foods do not support our results as they reported that spicy foods, was not associated with acne severity.Tehrani pupils had also the opinion that diet can exacerbate their acne: nutrition with sweets, nuts, chocolate, and oily foods were considered to significantly increase the severity of acne ${ }^{[27]}$. The current status of the relationship of diet and acne is not clear and under debate. On the one hand, the American Academy of Dermatology published recommendations in 2007 suggesting that caloric restriction has no benefit in the treatment of acne and that there is insufficient evidence to link the consumption of certain "food enemies" to acne ${ }^{[28]}$ On the other hand, other studies have suggested a rather close relationship between diet and acne. ${ }^{[29,}{ }^{30]}$ Evidence showing how diet may directly or indirectly influence the pathogenesis of acne has been provided recently ${ }^{[31,32]}$, but the relation between nutrition and acne still needs corroboration.

In the current study, $42.5 \%$ of cases of acne vulgaris have a positive family history of the condition. This finding is contestant with Abo El-fetoh et al., (2016) in Arar, KSA, reported that 46.7\% of cases of acne vulgaris have a positive family history of the condition ${ }^{[33]}$. This is also in consistence with the findings of a case control study conducted in Italy to assess the complex interconnection between dietetic variables and acne ${ }^{[34]}$ and findings of a study conducted in Jeddah, Saudi Arabia. ${ }^{[16]}$ who found an association between moderate and severe acne and positive family history.

In the present study, 57.8\% of cases reported impact of acne on social relations and $54.2 \%$ had an impact on self confidence. These findings are in accordance with Arar study which reported that $57.9 \%$ of acne cases had an impact on self-confidence and $49.5 \mathrm{had}$ an impact on social relations ${ }^{[33]}$. Findings of study in central $\mathrm{KSA}^{[17]}$ found that, in $46 \%$ of acne patients, acne had no, or minimal effect on their self-image and in most of the patients (73\%) had no or minimal effect on their relationships. 


\section{Conclusion and recommendations:-}

Acne was highly prevalent among adolescents and young females in Riyadh city, KSA. Several risk factors increased the appearance of acne including skin cleanliness, certain diets, stress and menstruation. There was clear seasonal variation; mainly in Summer. Therefore, a community-based multiple strategies are required to combat with increasing rate of acne vulgaris and its subsequent complications among adolescent and adult females in Riyadh city and to educate them about its causes and the risk factors aggravatingits development.

\section{Acknowledgement:-}

The authors would like to thank Dr. Wesam Mohamed Tharwat (Specialist of Dermatology and Venereology, Prince Hospital, Arar City), Anas Jamal Alkhanani (finished Internship, 6 October University), Sarah Jamal Alkhannani (intern, Northern Border University), Saja Jamal Alkhannani (student, Northern Border University), RahmahNaifAlzaid (student, College of Pharmacy, Aljouf University University) and Haifa LafiAlenzi (4 ${ }^{\text {th }}$ year medical students, Northern Border University) for their help in different steps of the research.

\section{References:-}

1. Chan JJ, Rohr JB. Acne vulgaris: yesterday, today and tomorrow. Australas J Dermatol 2000; 41 Suppl: S69S72.

2. Smithard A, Glazebrook C, Williams HC. Acne prevalence, knowledge about acne and psychological morbidity in mid-adolescence: a community-based study. Br J Dermatol 2001; 145: 274-279.

3. Vary JC Jr. Selected disorders of skin appendages; acne, alopecia, hyperhidrosis. Med Clin North Am. 2015; 99: 1195-1211.

4. Simpson NB, Cunliffe WJ. Disorders of sebaceous glands. In: Burns T, Breathnach S, Cox N, Griffiths C, editors. Rook's Textbook of Dermatology, $7^{\text {th }}$ ed., Oxford: Blackwell Publishing; 2004. p. 43.1-43.75.

5. Bhate K. Williams HC. "Epidemiology of acne vulgaris". Br J Dermatol:474-485.

6. Williams M, Cunliffe WJ. Explanation for premenstrual acne. Lancet 1973;2:1055-7.

7. Stoll S, Shalita AR, Webster GF, Kaplan R, Danesh S, Penstein A. The effect of the menstrual cycle on acne. J Am AcadDermatol 2001;45:957-60.

8. Khanna VN, Pandhi KR. Relationship of acne with menstrual period. Indian J DermatolVenereolLeprol 1991;57:138-40.

9. Harper JC. An update on the pathogenesis and management of acne vulgaris. J EurAcadDermatolVenereol 2004; 18: 435-439.

10. F. Poli, N. Auffret, C. Beylot et al., "Acne as seen by adolescents: results of questionnaire study in 852 French individuals," ActaDermato-Venereologica, vol. 91, no. 5, pp. 531-536, 2011.

I. A. Al-Hoqail, "Knowledge, beliefs and perception of youth toward acne vulgaris," Saudi Medical Journal, vol. 24, no. 7, pp. 765-768, 2003.

11. Stoll S., Shalita A. R., Webster G. F., Kaplan R., Danesh S., and Penstein A. "The effect of the menstrual cycle on acne," Journal of the American Academy of Dermatology, vol. 45, no. 6, pp. 957-960, 2001.

12. Adityan B, Thappa DM. Profile of acne vulgaris - A hospital-based study from South India. Indian J Dermatol Venereol Leprol. 2009; 75:272-278.

13. Hanisah A, Omar K, Shah SA. Prevalence of acne and its impact on the quality of life in school-aged adolescents in Malaysia. J Prim Health Care. 2009;1(1):20-25.

14. TutakneMA,Chari KVR. Acne, rosacea and perioral dermatitis. In: Valia RG, Valia AR, editors. $2^{\text {nd }}$ ed., Mumbai: Bhalani publishing House; 2003. p. 689-710

15. Al Mashat S, Al Sharif N, Zimmo S: Acne awareness and perception among population in Jeddah, Saudi Arabia. Journal of the Saudi Society of Dermatology \& Dermatologic Surgery 2013;17: 47-49.

16. Al Robaee AA. Prevalence, knowledge, beliefs and psychosocial impact of acne in University students in Central Saudi Arabia.Saudi Med J 2005 26(12):1958-1961.

17. Al-Ameer AM, Al-Akloby OM. Demographic features and seasonal variations in patients with acne vulgaris in Saudi Arabia: A hospital-based study. Int J Dermatol 2002;41:870-1.

18. Al-Kubaisy W, Abdullah NN, Kahn SM, Zia M.. Sociodemographic characteristics of acne among university students in Damascus, Syria. Epidemiology Research International. 2014; Article ID 974019, 4 pages (http://dx.doi.org/10.1155/2014/974019)

19. Stoll S, Shalita AR, Webster GF, Kaplan R, Danesh S, Penstein A (2001) The effect of the menstrual cycle on acne. J Am AcadDermatol 45:957-960. 
20. Z. El-Akawi, N. A.-L. Nemr, K. Abdul-Razzak, and M. Al-Aboosi, "Factors believed by jordanian acne patients to affect their acne condition," Eastern Mediterranean Health Journal, vol. 12, no. 6, pp. 840-846, 2006. View at Google Scholar . View at Scopus

21. D. H. Suh, J. W. J. Shin, S. U. Min, et al., "Treatment-seeking behaviors and related epidemiological features in Korean acne patients," Journal of Korean Medical Science, vol. 23, no. 6, pp. 969-974, 2008.View at Publisher · View at Google Scholar · View at Scopus

22. N. Hunger and C. Kumar, "A clinico-epidemiological study of adult acne: is it different from adolescent acne?" Indian Journal of Dermatology, Venereology and Leprology, vol. 78, pp. 335-341, 2012. View at Google Scholar

23. Bhate K. Williams HC. "Epidemiology of acne vulgaris". Br J Dermatol:474-485.

24. Magin P, Pond D, Smith W, Watson A. A systematic review of the evidence for 'myths and misconceptions' in acne management: diet, face-washing and sunlight. FamPract. 2005 10; 22(1):62-70.

25. Green J, Sinclair RD. Perception of acne vulgaris in final year medical student written examination answers.Austr J Dermatol. 2001;42(2):98-101.

26. Ghodsi SZ, Orawa ra Zouboulis CC. Prevalence, severity, and severity risk factors of acne in high school pupils: A community-based study. J Invest Dermatol 2009; 129: 009; 2141

27. Strauss JS, Krowchuk DP, Leyden JJ, Lucky AW, Shalita AR, Siegfried EC, et al. American Academy of Dermatology/American Academy of Dermatology Association. Guidelines of care for acne vulgaris management. J Am Acad Dermatol. 2007; 56:651-663.

28. 18.Smith RN, Mann NJ, Braue A, Mäkeläinen H, Varigos GA. A low-glycemic-load diet improves symptoms in acne vulgaris patients: a randomized controlled trial. Am J Clin Nutr. 2007; 86:107-115.

29. 19. Smith RN, Braue A, Varigos GA, Mann NJ. The effect of a low glycemic load diet on acne vulgaris and the fatty acid composition of skin surface triglycerides. J Dermatol Sci. 2008; 50:41-52.

30. Adebamowo CA, Spiegelman D, Danby FW, Frazier AL, Willett WC, Holmes MD. High school dietary dairy intake and teenage acne. J Am AcadDermatol. 2005;52(2):207-214.

31. DanbyFW. Acne and milk, the diet myth, and beyond. J Am Acad Dermatol. 2005; 52:360-362.

32. Abo El-Fetoh NM, Alshamari NG, Alenezi NG and Alenezi OG. Epidemiology of acne vulgaris in adolescent male students in Arar, Kingdom of Saudi Arabia. Journal of the Egyptian Public Health Association 2016, 91:144-149

33. DI Landro A, Cazzaniga S, Parazzini F, Ingordo V, Cusano F, Atzori L et al. Family history, body mass index, selected dietary factors, menstrual history, and risk of moderate to severe acne in adolescents and young adults. J Am Acad Dermatol.2012; 67(6):1129-1135. 